Revista

Ibero-Americana

de Estratégıa

\title{
ESTRATÉGIA MUNICIPAL PARA O DESENVOLVIMENTO LOCAL: O CASO DO PLANEJAMENTO ESTRATÉGICO DE BLUMENAU-SC
}

\author{
MUNICIPAL STRATEGY FOR LOCAL DEVELOPMENT: THE CASE OF THE \\ STRATEGIC PLANNING OF BLUMENAU-SC
}

\section{ESTRATEGIA MUNICIPAL PARA EL DESARROLLO LOCAL: EL CASO DE LA PLANIFICACIÓN ESTRATÉGICA DE BLUMENAU-SC}

\section{Sérgio Luiz do Amaral Moretti}

Doutor em Ciências Sociais e mestrado em Administração pela Pontifícia Universidade Católica de São Paulo - PUC/SP

Professor do Programa de Mestrado e Doutorado em Administração da Universidade Nove de Julho - UNINOVE

Email: moretti@uninove.br (Brasil)

\section{Fabricia Durieux Zucco}

Doutoranda do Programa de Mestrado e Doutorado em Administração pela Universidade Nove de Julho - UNINOVE

Professora da Universidade do Vale do Itajaí - UNIVALI

Email: fabriciazucco@hotmail.com (Brasil)

\section{Luciana Helena Crnkovic}

Doutoranda do Programa de Mestrado e Doutorado em Administração pela Universidade Nove de Julho - UNINOVE

Professora da Universidade Camilo Castelo Branco - UNICastelo

Email: crnkovic20@yahoo.com.br (Brasil)

\section{Nadia Kassouf Pizzinatto}

Doutora em Administração pela Fundação Getulio Vargas - FGV

Professora do Programa de Mestrado e Doutorado em Administração da Universidade Nove de Julho - UNINOVE

Email: nkp@ uninove.br (Brasil) 


\title{
ESTRATÉGIA MUNICIPAL PARA O DESENVOLVIMENTO LOCAL: O CASO DO PLANEJAMENTO ESTRATÉGICO DE BLUMENAU-SC
}

\section{RESUMO}

O planejamento estratégico (PE) constitui instrumento de relevância inquestionável para a gestão de municípios, principalmente após a regulamentação criada pela Lei de Responsabilidade Fiscal e, também o Estatuto da Cidade, que exercem constante pressão sobre os governos locais. Este estudo propõe-se analisar a importância do Planejamento Estratégico Municipal (PEM) para o desenvolvimento regional e, especificamente como instrumento de ligação entre a estratégia e os resultados a serem alcançados. Com este fim foi selecionada a cidade de Blumenau, SC, que adotou uma estratégia de crescimento por meio da exploração do turismo de eventos baseados em sua tradição germânica: a Oktoberfest, realizada na primavera e, a Sommerfest, no verão. A pesquisa de campo adotou o procedimento de explorar, de forma qualitativa o caso em questão por meio de entrevistas em profundidade com os envolvidos nas decisões, tanto na esfera governamental quanto nas autarquias envolvidas. Os resultados revelam o sucesso do governo municipal e da sociedade blumenauense em fortalecer a atividade turística de eventos articulada a um amplo PE. Esta sinergia tem nos últimos anos contribuido, decisivamente para o desenvolvimento local.

Palavras-chave: Estratégia; Planejamento Estratégico Municipal; Turismo de Eventos; Blumenau SC.

\section{MUNICIPAL STRATEGY FOR LOCAL DEVELOPMENT: THE CASE OF THE STRATEGIC PLANNING OF BLUMENAU-SC}

\begin{abstract}
Strategic planning (SP) is undoubtedly an important tool for the management of municipalities, mainly due to the consequential regulations established by the Fiscal Responsibility Law, and also the City Statute, which exercise constant pressure on local governments. This study proposes to examine the importance of Municipal Strategic Planning (MSP) for regional development, and specifically as a means of correlating strategy and the results that shall be achieved. Therefore, we selected the city of Blumenau, SC, which adopted a growth strategy through capitalizing on touristic events based on its German tradition: Oktoberfest, held in the spring and Sommerfest in the summer. The field research adopted the procedure to explore, qualitatively, the case in question through interviews with those directly involved in the decision-making process, within the government and the authorities involved. The results indicate the success of the municipal government and Blumenau's community in improving its touristic activities concerning the aforementioned events by incorporating an ample SP. In recent years, this collaboration has made an influential contribution to local development.
\end{abstract}

Keywords: Strategy; Municipal Planning Strategy; Touristic Events; Blumenau - SC.

Revista Ibero-Americana de Estratégia - RIAE, São Paulo, v. 9, n. 2, p. 168-190, mai./ago. 2010. 
ESTRATEGIA MUNICIPAL PARA EL DESARROLLO LOCAL: EL CASO DE LA PLANIFICACIÓN ESTRATÉGICA DE BLUMENAU-SC

\section{RESUMEN}

La planificación estratégica (PE) es un instrumento de una incuestionable relevancia para la gestión de municipios, principalmente después de la reglamentación creada por la Ley de Responsabilidad Fiscal y, también por el Estatuto de la Ciudad, que ejercen constante presión sobre los gobiernos locales. Este estudio propone analizar la importancia de la Planificación Estratégica Municipal (PEM) para el desarrollo regional y, específicamente como instrumento de enlace entre la estrategia y los resultados a ser alcanzados. Con esta finalidad fue seleccionada la ciudad de Blumenau, SC, que adoptó una estrategia de crecimiento por medio de la explotación del turismo de eventos basados en su tradición germánica: la Oktoberfest, realizada en la primavera y, la Sommerfest, en el verano. La investigación de campo adoptó el procedimiento de explorar, de forma cualitativa el caso en cuestión, mediante entrevistas en profundidad con las personas involucradas en las decisiones, tanto en la esfera gubernamental como en las autarquías relacionadas. Los resultados revelan el suceso del gobierno municipal y de la sociedad de Blumenau en fortalecer la actividad turística de eventos articulada a una amplia PE. Esta sinergia ha contribuido en los últimos años, decisivamente para el desarrollo local.

Palabras-clave: Estrategia; Planificación Estratégica Municipal; Turismo de Eventos; Blumenau SC. 
Estratégia Municipal para o Desenvolvimento Local: O Caso do Planejamento Estratégico de Blumenau-SC

\section{INTRODUÇÃO}

Ao dar sustentação metodológica para estabelecer a melhor direção a seguir, o PE constitui instrumento de relevância inquestionável para a gestão de municípios, principalmente após a regulamentação criada pela Lei de Responsabilidade Fiscal e também o Estatuto da Cidade, que exercem constante pressão sobre os governos locais (Rezende e Castor, 2006). Para se adaptar ao marco regulatório, o PE representa para os municípios uma forma de a sociedade exercer poder sobre o seu futuro (Ingelstam,1987), ao mesmo tempo que se torna um processo coletivo capaz de transformar a realidade e delinear uma rota segura para a construção de um futuro mais promissor (Buarque, 2002).

Os municípios que contam com atrações locais, naturais ou folclóricas podem oferecer opções para gerar um fluxo turístico considerável com consequente impacto na economia. Nesse contexto o turismo precisa deixar de ser uma obra do acaso e passar a ser planejado e executado de forma profissional, ou seja, ser encarado como um negócio e como em qualquer outro negócio, o seu sucesso é dependente da boa gestão das organizações do setor (Tomio, 2000, p. 40). O desafio é grande, pois o fortalecimento da capacidade empreendedora do turismo depende da articulação entre poder público, iniciativa privada e sociedade civil, num movimento sinérgico das múltiplas escalas do poder local (Acselrad, 2002).

O turismo de eventos está em um momento favorável no Brasil, com crescimento anual de cerca de $10 \%$, tornando-se responsável por uma receita em torno de 44 bilhões de reais e gerando 3 milhões de empregos diretos, indiretos e terceirizados (Fazzini e Palladino, 2003). O setor é potencializado pelo segmento de festas e eventos em geral, que vêm se consolidando e aumentando o poder de atrair e encantar turistas, a ponto de se tornarem megaeventos de fama nacional e internacional. Eventos como festivais e celebração - atrelados à tradição e aos costumes locais , por serem diferenciados, transformam-se em valores referenciais, constituindo-se em catalisadores para movimentação de visitantes (Pereira, 2003, p. 98).

Em sintonia com esse cenário, o município de Blumenau se apresenta como instigante objeto de pesquisa no campo do PE municipal e da gestão do turismo. Famoso destino do Vale Europeu - região turística que reúne 32 cidades de Santa Catarina - tem como principal atração a Oktoberfest, a maior festa alemã das Américas. Nesse território, apelidado Alemanha tropical, concentra-se este estudo.

O objetivo que orienta esta pesquisa é analisar a importância do Planejamento Estratégico Municipal (PEM) para o desenvolvimento regional e, especificamente como instrumento de ligação 
entre a estratégia e os resultados a serem alcançados. Com este fim foi selecionada a cidade de Blumenau, SC, que adotou uma estratégia de crescimento por meio da exploração do turismo de eventos baseados em sua tradição germânica.

O artigo está organizado da seguinte forma: na próxima seção será feita uma revisão da literatura de Estratégia e Planejamento Estratégico Municipal e sua importância para a saúde financeira dos municípios, integração com outros planos e etapas a serem seguidas, bem como sua aplicação ao setor de turismo. Posteriormente segue a metodologia aplicada ao trabalho, a análise de dados sobre a construção do PEM e as considerações finais.

\subsection{ESTRATÉGIA PARA O DESENVOLVIMENTO LOCAL}

A formulação estratégica envolve o desenho de uma ideia original e apropriada para garantir um direcionamento eficaz para a conquista de objetivos pretendidos. Contudo, o conceito sofre adaptações conforme os autores justificam o nível em que é adotada dentro de um empreendimento ou organização. Costa, Fishmann, Silva (2008) foram muito felizes em estabelecer esta questão considerando 3 níveis de aplicação da estratégia: 1) corporativo, que fornece a direção à organização como um todo; 2) competitivo, que trata de averiguar o grau de competitividade em relação aos concorrentes de um mesmo negócio; e, 3) funcional, que busca o equilíbrio entre recursos, tempo e capacitações necessárias para transformar a estratégia (a ideia principal) em ações ajustadas para atender aos seus propósitos (Costa, Fishmann, Silva, 2008, p. 2).

As principais escolas de estratégia, como a do Posicionamento (Mintzberg, 1994; Minzberg, Ahlstrand e Lampel, 2000) e a da Competição (Porter, 1986), buscam modelos para facilitar o seu entendimento, partindo de concepções genéricas de aplicação; elas são assim denominadas por poderem servir a qualquer empreendimento, organização pública ou privada (Weber, 2006). O exemplo das estratégicas genéricas de Porter (1986) é, talvez, o mais conhecido; o autor conceitua três formas distintas de competir: diferenciação, custos e foco. As duas primeiras se ajustam à competição em grandes mercados e a terceira é adequada para segmentos menores de negócios. No caso da diferenciação, a organização busca competir pela qualidade diferenciada de seus produtos ou serviços, o que lhe permite cobrar um preço premium dos seus clientes. Já no segundo caso, a de custos, a organização compete por meio de sistemas produtivos e organizacionais superiores que permitem operar a custos abaixo da média do setor e, portanto, competir por preço. Finalmente, no caso do foco, a organização busca competir em segmentos específicos e reduzidos de mercados por meio de uma estratégia baseada em diferenciação ou custo.

Revista Ibero-Americana de Estratégia - RIAE, São Paulo, v. 9, n. 2, p. 168-190, mai./ago. 2010. 
Estratégia Municipal para o Desenvolvimento Local: O Caso do Planejamento Estratégico de Blumenau-SC

Para Mintzberg, Ahlstrand e Lampel (2000), seja qual for o modelo a ser adotado, as estratégias apresentam características pelas quais podem ser, na visão dos autores, igualmente agrupadas. O tipo de estratégia denominada pretendida se realiza quando é possível vinculá-la ao objetivo, ou seja, tem-se uma solução específica e diretamente ligada ao que se pretende realizar. A estratégia pode ser também deliberada, quando são planejadas segundo um processo racional e formal e seguem padrões conhecidos e aceitos. Porém a estratégia pode ser não realizada, assim denominada por não ter ocorrido. Finalmente, a estratégia pode ser emergente, quando surge bottom up, ou seja, de baixo para cima a partir de ações isoladas ou não conectadas, mas que consegue formar um conjunto organizado de ideias e ser colocada em prática.

Nas propostas dos autores acima, a estratégia pode ser relacionada tanto com os recursos adotados quanto com as competências da organização. Para o caso em destaque é importante ressaltar a questão dos recursos como central na decisão de Blumenau em explorar o turismo de eventos. Para isso torna-se importante recorrer à linha de pensamento estratégico denominada Visão Baseada em Recursos (Amit e Schoemaker, 1993) que postula serem os recursos mais importantes até que a própria estratégia. Para os autores desta linha, recursos são tanto capacitações quanto ativos (Day, 1994) e também conhecimentos que devem ser difíceis de imitar e, ainda, serem duráveis e insubstituíveis (Barney, 1991). A combinação dessas características definirá a vantagem competitiva a ser explorada (Rumelt, Schendel, Teece, 1994) e o valor estratégico criado (Mathews, 2002).

Contudo, não se deve perder de vista que o objetivo da estratégia quase sempre está vinculado à busca de vantagens competitivas duradouras, refletidas em uma oferta adequadamente configurada... A opção estratégica mais adequada, entretanto, deverá estar em conformidade com os objetivos e interesses particulares [de] empresas... setores de atividade... estruturas $e$ circunstâncias ambientais (Weber, 2006, p. 13). Assim, para o caso de Blumenau, os recursos são fundamentais, já que propiciam uma combinação poderosa de natureza, tradição alemã e infraestrutura de hotéis, restaurantes e serviços em geral.

A prática leva à perfeição. $\mathrm{O}$ resultado para as comunidades que utilizam o $\mathrm{PE}$ sistematicamente é ter a oportunidade de poder avaliar seus impactos e a relação entre os diferentes setores envolvidos, tais como serviços, recepção dos turistas pela comunidade e estrutura de hospedagem alimentação e transporte (Silva e Costenaro, 2004). O envolvimento da comunidade nesse tipo de planejamento é crucial, como pregam Licklorish e Jenkins (2000), e deve levar em conta o ambiente global (Seddigli e Theosharous, 2002) interligado aos aspectos econômicos locais (Pizam, 1996; Mathieson e Wall, 2000).

Revista Ibero-Americana de Estratégia - RIAE, São Paulo, v. 9, n. 2, p. 168-190, mai./ago. 2010. 
Dentro dessa abordagem, Blumenau é capaz de explorar uma combinação de diversos públicos, que já se encontram ajustados em uma rede voltada ao objetivo de gerar valor para os empreendimentos e para o município. Essa rede de valor se torna ferramenta de desenvolvimento de negócios, com os agentes desempenhando papéis específicos em diversos setores que são potenciais geradores de valor para o município. O modelo desenvolvido por Brandenburger; Nalebuff (1995) é bastante adequado para se estudar o caso, pois propõe o conceito de rede de valor montada a partir do interesse de diversos agentes convergindo para o desenvolvimento de um empreendimento. A Figura 1 adapta o modelo proposto pelos autores, colocando no centro da rede de valor o município de Blumenau.

Figura 1 - Rede de Valor para o Turismo em Blumenau.

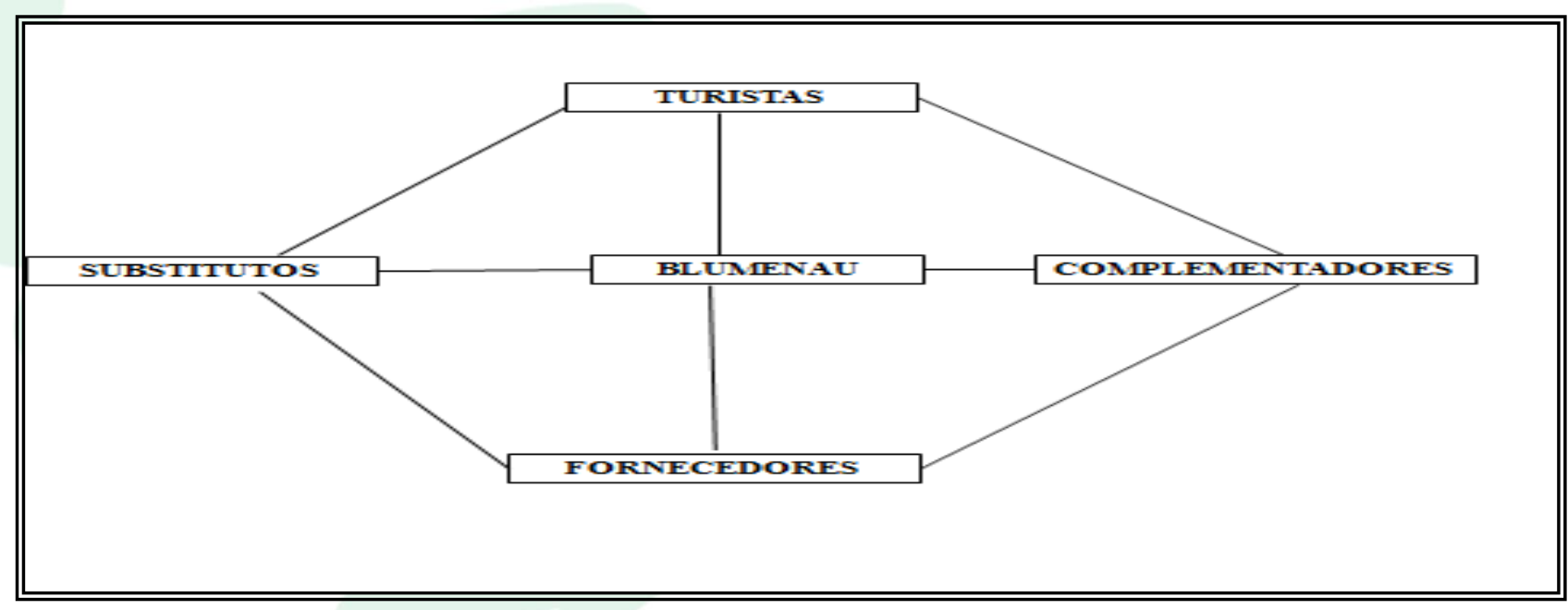

Fonte: Adaptado pelos autores de Brandenburger e Nalebuff (1995).

Pelo centro do modelo cruzam dois eixos: um vertical, formado pelos clientes (turistas) em um polo e os fornecedores em outro, e um eixo horizontal, constituído pelos substitutos (concorrentes do município para a preferência dos turistas) em um polo, e em outro os complementadores. Estes últimos são todos os que, mesmo não estando envolvidos diretamente nos empreendimentos, contribuem para o seu sucesso, por exemplo, a simpatia e a eficiência na disposição em ajudar por parte da população, o que se reflete em todos os outros serviços oferecidos pela cidade.

No modelo deve-se considerar que o objetivo é dirigido para todos os envolvidos ganharem sua parcela pelo esforço realizado. No caso estudado, este esforço é reforçado pelo poder de agenciamento do governo municipal que é capaz de organizar o esforço coletivo e traçar linhas de 
fomento aos negócios. Ele serve como incentivador dos vários processos envolvidos e tem a responsabilidade de elaborar o $\mathrm{PE}$, que se torna o grande instrumento organizador dessas iniciativas (Besanko, Dranove e Shanley, 2000).

\subsection{PLANEJAMENTO ESTRATÉGICO MUNICIPAL (PEM)}

Após a elaboração de uma estratégia que sirva aos seus propósitos de desenvolvimento local - aumento da qualidade de vida, conservação dos recursos naturais e do meio ambiente, economia competitiva, entre os principais -, o maior desafio dos governos municipais é garantir a execução das ideias. O sucesso dessa empreitada depende do PE, já que ele pode contribuir para a mobilização das energias sociais e se constituir em referência para a implementação das ações (Buarque, 2002).

Os municípios brasileiros são, cada vez mais, exigidos no que se refere à governança, ou seja, na transparência das contas públicas e no planejamento de suas ações, tendo que obedecer à Constituição Federal e à Lei de Responsabilidade Fiscal, além de cumprir exigências do Estatuto da Cidade e da Lei Orgânica Municipal. Todas essas pressões, fortalecidas pela cobrança dos munícipes em relação às respostas de suas demandas, podem ser minimizadas com a elaboração e a implementação do Planejamento Estratégico Municipal (PEM), do Planejamento Plurianual Municipal (PPAM) e do Plano Diretor Municipal (PDM), com a participação da sociedade civil.

Os instrumentos do PDM e do PEM, um por força de lei, outro por opção metodológica ou de gestão, representam mecanismos de planejamento [...], constituindo mesmo o que se pode chamar de utopias contemporâneas para a questão urbana brasileira (Ultamari e Rezende, 2008, p. 718). Contudo, mais do que agente realizador, a prefeitura deve funcionar como articuladora e facilitadora dos objetivos, estratégias e ações que, segundo Dowbor (1995), têm eficácia maior quando o poder público é apenas um dos agentes envolvidos no projeto de desenvolvimento local incorporado pela sociedade.

A viabilização desses planos e planejamentos municipais terá como fundamentos uma equalização dos recursos humanos, financeiros, naturais, tecnológicos e culturais, e também as informações disponíveis para embasar a tomada de decisão (Rezende e Castor, 2006). No PEM e PDM se destacam problemas, objetivos, estratégias e ações, viabilidades, controle e gestão; no PPAM, programas, projetos, recursos financeiros, parcerias público-privadas, indicadores e resultados. Aspecto importante nesse contexto é o orçamento, considerado por Almeida e Cruz (2002) como o produto de maior visibilidade do planejamento da instituição pública, por refletir as

Revista Ibero-Americana de Estratégia - RIAE, São Paulo, v. 9, n. 2, p. 168-190, mai./ago. 2010. 
ações e esforços pretendidos pelo governo e o grau de coerência dessas despesas com a receita estimada. De fato, é a tradução do PE sempre pensado no longo prazo, para o plano tático de curto prazo, ou seja, as ações imediatas que precisam ser implementadas.

Deve-se lembrar que os planos precisam estar atentos às restrições orçamentárias (Furtado, 2009), já que a Constituição Federal determina que todo orçamento público precisa ser elaborado a partir de três etapas que compõem o ciclo orçamentário: Plano Plurianual (PPA), Lei de Diretrizes Orçamentárias (LDO) e Lei Orçamentária Anual (LOA).

O PPA estabelece os projetos e os programas de longa duração do governo, definindo objetivos e metas da ação pública para um período de quatro anos. A LDO define as metas e prioridades da administração pública, incluindo as despesas de capital para o exercício financeiro subsequente, orienta a elaboração da Lei Orçamentária Anual, dispõe sobre as alterações na legislação tributária e estabelece a política de aplicação das agências financeiras oficiais de fomento. A LOA detalha a aplicação dos recursos do município em obras e ações para o exercício seguinte. Ela é elaborada com base nas diretrizes, anteriormente apontadas pelo PPA e pela LDO, ambos definidos pelo Executivo, a partir de discussões com a comunidade.

Todas essas questões convergem para o pressuposto de que o PE é também um processo ordenado e sistemático de decisão, que lhe confere uma conotação técnica e racional de formulação e suporte para as escolhas da sociedade. Dessa forma, ele incorpora e combina uma dimensão política e uma dimensão técnica (Buarque, 2002, p. 82). Para que o turismo definido por Moesch (2000, p. 9) como a combinação de inter-relacionamentos entre a produção e serviços possa contribuir para a qualidade de vida das comunidades, é fundamental uma gestão capaz de potencializar a soma de fenômenos e relações originados da interação de turistas, empresas, governos locais e comunidades anfitriãs, no processo de atrair e receber turistas e outros visitantes, como postulam Goeldner, Ritchie e Mcintosh (2002, p. 23).

Para que o PE seja baseado em fatos e não em opiniões, a literatura propõe instrumentos de análise. Um deles é de autoria de Hooley, Saunders e Piercy (2001) e utilizado pela prefeitura de Blumenau. Esse instrumento propõe-se a reunir em um mesmo documento as auditorias interna e externa referentes ao fenômeno estudado e relacionar seus pontos fortes e fracos, relativos à estratégia que se pretende adotar. De fato, ele é um instrumento que reúne as informações mais pertinentes à tomada de decisão de uma forma simples e objetiva. Os autores sugerem partir de 3 questões fundamentais: 1) definir a finalidade ou missão do empreendimento; 2) analisar o perfil das capacidades, no caso do município e; 3 ) analisar o setor onde o empreendimento será realizado,

Revista Ibero-Americana de Estratégia - RIAE, São Paulo, v. 9, n. 2, p. 168-190, mai./ago. 2010. 
Estratégia Municipal para o Desenvolvimento Local: O Caso do Planejamento Estratégico de Blumenau-SC

no caso o turismo (Hooley, Saunders e Piercy, 2001, p. 31). Um exemplo prático aplicado pelo PEM de Blumenau será mostrado na seção de Análise e Discussão de Resultados.

Para finalizar a literatura pertinente ao caso em questão, pode-se notar durante a análise do PEM que o processo de acompanhamento do desempenho do PE foi muito facilitado pela utilização de um instrumento já conhecido e colocado em prática anteriormente pelos gestores públicos de Blumenau, o Balanced Scorecard - BSC. Criado em 1992 por Kaplan e Norton (2000), o método se propõe a contribuir para o planejamento e também servir como um painel de controle para a monitoração das ações previstas. Segundo os autores, o BSC busca mostrar o equilíbrio entre as diversas ações e os objetivos previstos, assim como entre as medidas financeiras e não financeiras e os indicadores de tendência. A Figura 2 mostra a relação entre as diversas áreas que devem ser consideradas no planejamento e posteriormente monitoradas.

Figura 2 - Áreas de decisão e monitoramento do BSC.

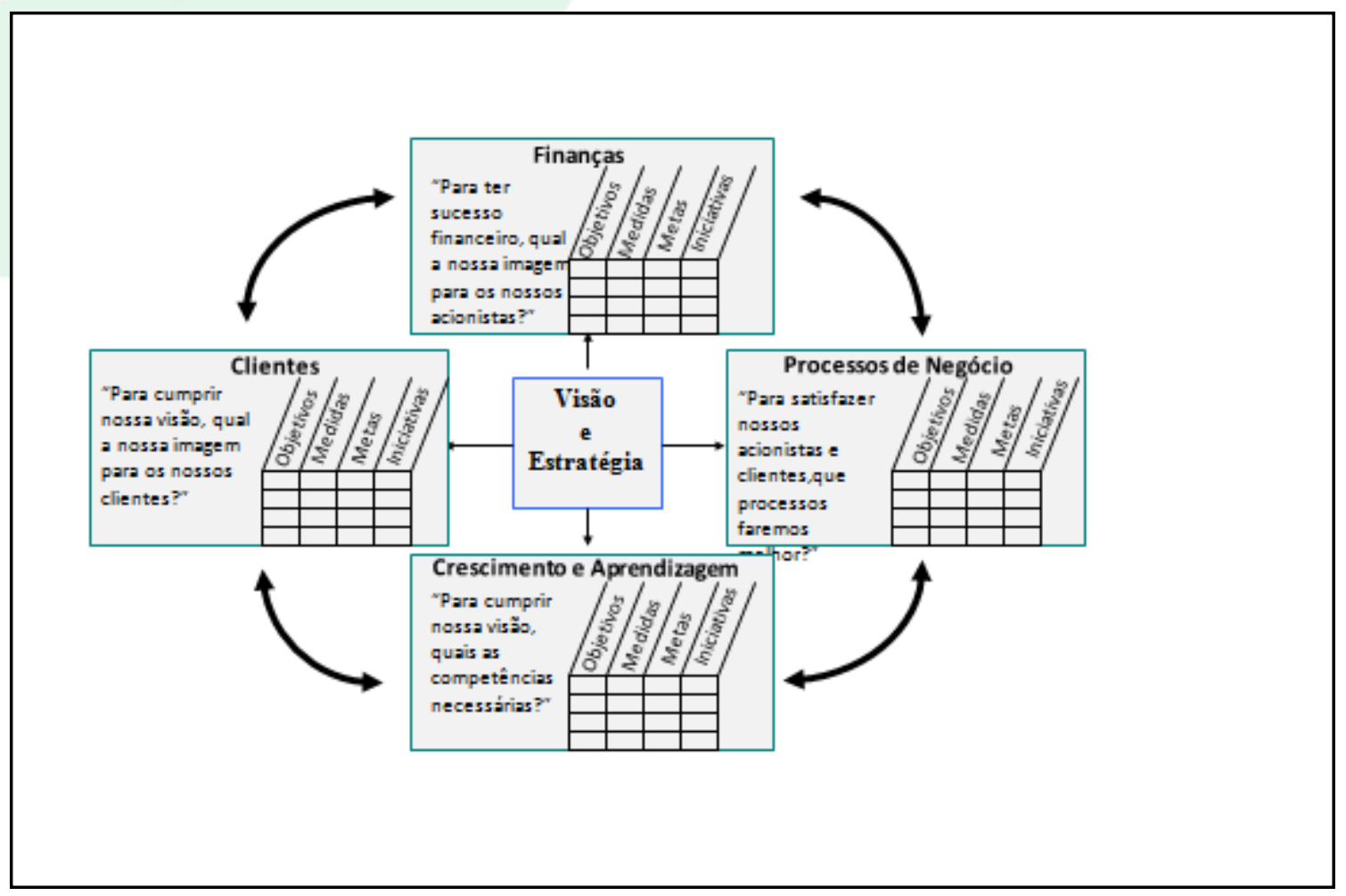

Fonte: Adaptado pelos autores de Kaplan e Norton (2000).

Os autores lembram que cada uma dessas áreas representa uma rede de atividades e processos gerenciais, conforme sugerido na Figura 2, e que o foco em apenas uma dessas perspectivas limita o atingimento das metas organizacionais (p.37). Portanto, a implementação da 
estratégia pressupõe uma forte integração de diversas áreas em prol do objetivo comum de qualquer empreendimento.

A revisão da literatura específica para o tema feita até aqui mostra que o PE se desenvolve a partir da estratégia central para um dado empreendimento e suas ações devem ser implementadas segundo um roteiro de procedimentos e monitoramento. Toda ação deve ser alvo de controle para se obter feedback sobre o seu desempenho, facilitando as correções de curso e seu aperfeiçoamento.

\subsection{METODOLOGIA}

O procedimento metodológico para atender aos objetivos da pesquisa foi um estudo de caso utilizado para analisar a gênese, desenvolvimento e implantação do PEM de Blumenau sobre o qual seguem algumas características importantes para o entendimento da questão. Trata-se de um município localizado no nordeste de Santa Catarina e centro econômico da microrregião do Vale do Itajaí (formada por 16 municípios). No seu território de 519,8 Km² reside uma população de 301 mil habitantes responsáveis por uma economia baseada no comércio, na prestação de serviços, no turismo e na atividade industrial sustentada em seis pilares: têxtil/vestuário, alimentação, metalurgia, produção fumageira, informática e construção civil.

Conforme informações da Santa Catarina Turismo (Santur, 2009), empresa vinculada à Secretaria de Estado de Turismo, o impacto econômico do turismo regional pode ser ampliado, já que Blumenau está integrada na região turística Vale Europeu, composta por 32 cidades de colonização europeia e é visitada por cerca de 1 milhão de pessoas em todas as épocas do ano.

$\mathrm{Na}$ década de 1980, após duas enchentes catastróficas para a economia e a população da cidade, a comunidade e, o poder público se uniram para reproduzir uma festa que existia há cerca de 200 anos em Munique, na Alemanha: a Oktoberfest. O evento ganhou projeção internacional, consagrando-se como a segunda maior festa de tradição alemã do mundo.

A Oktoberfest acontece no Parque Vila Germânica administrado por uma fundação municipal, cuja estrutura possui área total de $39 \mathrm{mil} \mathrm{m}^{2}$ assim dividida: o Centro de Eventos com 26 mil m² construídos e a Vila Germânica, conjunto de lojas comerciais, restaurantes, choperias, casa de lanches e café colonial, museu, serviços e inúmeras outras atrações para receber turistas e moradores da região. A instalação está localizada no Distrito Turístico, a dois quilômetros do centro da cidade, com várias vias de acesso e interligado a todos os bairros do município.

Aplicando-se a recomendação de Flick (2009) observou-se que o caso de Blumenau possui os requisitos para um estudo de caso, pois 1) se pretende compreender a construção da estratégia 
municipal como princípio do conhecimento; 2) procura-se pelo entendimento dos fatos ocorridos durante o processo; 3) usou-se a ciência baseada em texto como base da investigação para fundamentar a pesquisa; e 4) buscou-se comparar as teorias sobre o tema com a prática encontrada em busca de evidências para a construção de outras teorias.

O método escolhido para conduzir a fase empírica foi o estudo de caso, visto que essa abordagem tem por objetivo investigar um fenômeno no seu real contexto, no qual os limites entre o fenômeno e o contexto não são claramente percebidos, sendo necessária a utilização de diversas fontes de evidência, entrevistas, arquivos, documentos. Sua adoção é adequada quando são propostas questões de pesquisa do tipo "como" e "por que" e quando o pesquisador tem pouco controle de uma situação inserida em contextos sociais (Yin (2001, p. 32). Eisenhardt (1989) defende que esse método permite a comparação dos resultados levantados com a literatura existente, fato que amplia a qualidade do trabalho científico. Durante o processo, o pesquisador tem contato com questões relacionadas ao que contradiz, ao que é convergente e ao porquê dos fatos.

Seguindo o protocolo recomendado por Yin (2001), a pesquisa envolveu três fases distintas: 1) seleção do caso, com definição de procedimentos e instrumentos a serem adotados na coleta de dados, incluindo a elaboração do roteiro de entrevista dirigida a gestores municipais; 2) coleta de evidências para compor o material sobre o caso por meio de análise de documentos da prefeitura e órgãos relacionados, assim como o desenvolvimento de entrevistas com pessoas relacionadas ao fenômeno investigado; e 3) a última fase do estudo consistiu na análise dos dados obtidos à luz da teoria selecionada com interpretação dos resultados.

Como instrumento de coleta de dados foi elaborado um roteiro para entrevista semiestruturada em profundidade que, como define Triviños (1992), é aquela guiada por uma relação de questões de interesse, apoiadas por teorias que orientam a pesquisa. $O$ instrumento procurou enfocar as experiências subjetivas das pessoas entrevistadas, de modo a obter suas definições e impressões do processo do qual participaram (Salem, Jones e Morgan, 2004).

A partir desses referenciais, os tópicos abordados no instrumento foram: 1) descrição e caracterização do processo de elaboração do PEM; 2) aspectos relativos aos processos decisórios e investimentos; 3) características das ações desenvolvidas: suas abordagens, estrutura de implementação e gerenciamento; e 4) fatores de sucesso identificados e dificuldades associadas à implementação das ações.

$\mathrm{Na}$ pesquisa foram entrevistados cinco gestores de órgãos municipais diretamente vinculados à prefeitura de Blumenau. As autoridades entrevistadas foram: o prefeito de Blumenau, o chefe da Defesa Civil Municipal, os secretários de Turismo, Administração Municipal e o de

Revista Ibero-Americana de Estratégia - RIAE, São Paulo, v. 9, n. 2, p. 168-190, mai./ago. 2010. 
Gestão, e o Presidente do Parque Vila Germânica (autarquia municipal responsável pela organização do Oktoberfest). Todos os entrevistados foram escolhidos por ocuparem cargos em órgãos fundamentais na gestão municipal diante do desastre ocorrido na cidade.

Para facilitar a análise dos dados coletados e assegurar sua confiabilidade e validação, recorreu-se ao recurso de triangular as diversas fontes pesquisadas. Com isso, pretendeu-se averiguar a consistência interna dos dados por meio de comparações (Flick, 2009). Foram utilizados: documentos da prefeitura e das autarquias, artigos e matérias de jornal. Todo o material foi analisado à luz das entrevistas realizadas e da teoria estudada.

\subsubsection{O CASO DO PROJETO BLUMENAU 2020}

Em 2005, após inúmeras reuniões com vários setores da sociedade blumenauense, surgiu o PEM, conhecido como Projeto Blumenau 2020, cujo principal objetivo era modernizar a administração pública municipal, promover o desenvolvimento econômico e social sustentável e ampliar a liderança de Blumenau no contexto catarinense. Seus organizadores adotaram como lema do PEM: "Tornar Blumenau a melhor cidade do país para viver".

A estratégia principal e o eixo norteador do PEM 2005-2020 foram desenvolver o turismo de lazer e eventos, aproveitando as características naturais, a imagem de organização e a tradição alemã da cidade. $\mathrm{O}$ desencadeador do processo e grande desafio era acabar com a sazonalidade representada pela Oktoberfest. No caso de Blumenau podem ser aproveitadas a pujança industrial e a imagem de organização e disciplina do povo blumenauense. Além do ganho potencial representado pela integração dos roteiros turísticos de toda a região do Vale Europeu, com seus componentes naturais, culturais, históricos, gastronômicos, aventuras e compras.

O foco no turismo se tornara uma escolha natural para a cidade, mas também se apoiara no crescimento dessa atividade e seu poder multiplicador. O turismo se tornou um dos principais motores da economia, incentivando o desenvolvimento de outras atividades econômicas, notadamente as indústrias de construção civil, hotelaria e transportes, constituindo-se, de fato, em uma grande cadeia produtiva de serviços (Swarbrooke, 2000). Ao abordar a mesma questão, Krippendorf (2000, p. 47) argumenta que harmonizar o desenvolvimento turístico implica, antes de tudo, desembaraçar o nó dos interesses, muitas vezes contraditórios, e estabelecer uma ordem de prioridades. $\mathrm{O}$ autor considera duas interfaces principais nesse processo: a ação dos órgãos públicos e privados para melhorar a infraestrutura e a participação da comunidade no planejamento turístico - esta última apontada por Irving (2002) como elemento essencial para a sustentabilidade do processo.

Revista Ibero-Americana de Estratégia - RIAE, São Paulo, v. 9, n. 2, p. 168-190, mai./ago. 2010. 
Estratégia Municipal para o Desenvolvimento Local: O Caso do Planejamento Estratégico de Blumenau-SC

Com a expansão da atividade turística nos últimos anos a oferta de destinos turísticos se multiplicou, principalmente estimulada pela facilidade de crédito, transporte e comunicações. Tal fato significa maior concorrência nas opções e maiores níveis de exigência pelos turistas em todos os quesitos que envolvem a sua estada no local. A situação atual se agrava pela constatação de que, além dessas dificuldades, sabe-se que é difícil manter a fidelidade dos visitantes, sempre em busca de locais e atrações diferentes. Por essas razões deve-se evitar decisões intuitivas e improvisadas para um público cada vez mais exigente (Tomio, 2000).

Buscou-se, assim, a partir desse fundamento, apostar na diferenciação de Blumenau como capaz de oferecer serviços superiores, portanto satisfazer as necessidades dos turistas em termos de hospedagem, alimentação, transporte e boas atrações. A aderência com a proposta de Porter (1986) é evidente, assim como ao modelo proposto por Brandenburger e Nalebuff (1995), de contar com os complementadores para fechar o ciclo de atendimento aos turistas.

Importa assinalar que as ações do PEM foram reavaliadas por causa das enchentes de novembro de 2008. Segundo o secretário de Orçamento e Gestão, Marcel Hugo, a recuperação da cidade exigiu ações e investimentos prioritários previstos no PPA, que para essa finalidade disponibilizou R\$ 4,2 bilhões. Ele informa que o PPA 2010/2013 absorveu demandas geradas pela tragédia de novembro de 2008 e que projetos como o novo plano de contingência, os estudos geológicos e geotécnicos, as obras de reconstrução e a ampliação dos planos de habitação tiveram que ser cotejados e os investimentos equivalentes, incluídos.

O exemplo mostra que o PEM representa um plano estratégico contínuo, sistemático e contingencial, com flexibilidade para reagir a um ambiente dinâmico e às vezes ameaçador. Ele não é visto apenas como uma previsão sobre o futuro, mas sim como um conjunto de respostas a eventos variados que podem ou não se concretizar.

De acordo com Marcel Hugo, o PEM também prevê o estabelecimento de políticas públicas de longo prazo, consolidando-as no PDM, que obedece ao Estatuto da Cidade. Um dos objetivos estratégicos é implantar uma política habitacional que garanta a ocupação da cidade com respeito ao meio ambiente e qualidade de vida. Somada a isso, a revisão do Código Tributário Municipal e do Código de Posturas, além dos esforços para regularização fundiária, completa um conjunto de ações que estabelecem novas políticas públicas. Tais políticas estão sendo construídas com a participação ativa da população e assim se transformam em rumos coletivos do município, muito mais que decisões do governo. No que se refere ao estabelecimento e cumprimento de metas e objetivos, os entrevistados foram unânimes ao afirmarem a dificuldade nesses processos, pois muitas ações dependem de recursos oriundos do Estado e da União.

Revista Ibero-Americana de Estratégia - RIAE, São Paulo, v. 9, n. 2, p. 168-190, mai./ago. 2010. 
A base do desenvolvimento do PEM foi o procedimento recomendado por Hooley, Saunders e Piercy (2001), conforme apresentada na Revisão da Literatura. Os elaboradores do PEM denominaram o instrumento proposto pelos autores de Matriz de Posicionamento Estratégico. A Tabela 1 mostra os resultados de sua aplicação.

Tabela 1 - Matriz do Posicionamento Estratégico.

\begin{tabular}{|c|c|c|}
\hline AUDITAGEM INTERNA & \multicolumn{2}{|c|}{ AUDITAGEM EXTERNA } \\
\hline PONTOS & OPORTUNIDADES & AMEAÇAS \\
\hline $\begin{array}{l}\text { Fortes } \\
\text { - Região turística do Vale do } \\
\text { Itajaí } \\
\text { Hospedagem e atendimento ao } \\
\text { cliente } \\
\text { - Know-how na organização de } \\
\text { festas típicas alemãs } \\
\text { - Identidade cultural } \\
\text { - Participação da comunidade } \\
\text { nas decisões } \\
\text { Infraestrutura para promoção } \\
\text { de eventos }\end{array}$ & $\begin{array}{l}\text { Desenvolvimento } \\
\text { - Turismo de eventos em } \\
\text { crescimento } \\
\text { - Imagem da cidade } \\
\text { - Concentração de turistas nas } \\
\text { cidades vizinhas } \\
\text { - Geração de emprego } \\
\text { - Fortalecimento da marca } \\
\text { - Aumento da qualidade de vida da } \\
\text { comunidade } \\
\text { - Diversificação do setor de serviços }\end{array}$ & $\begin{array}{l}\text { Manutenção } \\
\text { - Falta de treinamento das pessoas da } \\
\text { comunidade no turismo regional } \\
\text { - Malha viária precária } \\
\text { - Sazonalidade } \\
\text { - Orçamento para turismo (PPA) } \\
\text { - Clima } \\
\text { - Variedade nas opções de lazer nas } \\
\text { cidades vizinhas }\end{array}$ \\
\hline $\begin{array}{l}\text { Fracos } \\
\text { - Fluxo turístico concentrado em } \\
\text { um único mês (outubro) } \\
\text { - Malha viária precária; } \\
\text { - Recursos limitados para } \\
\text { divulgação }\end{array}$ & $\begin{array}{l}\text { Crescimento } \\
\text { - Novas festas típicas } \\
\text { - Inovar nas expectativas } \\
\text { - Parcerias com os hotéis e pousadas } \\
\text { do litoral na temporada de praias } \\
\text { - Serviços personalizados } \\
\text { - Linha de serviços culturais } \\
\text { - Mobilização comunitária }\end{array}$ & $\begin{array}{l}\text { Sobrevivência } \\
\text { - Reduzir custos diretos } \\
\text { - Direcionar investimentos de forma } \\
\text { focada } \\
\text { - Captação de patrocínios } \\
\text { - Desenvolvimento de parcerias }\end{array}$ \\
\hline
\end{tabular}

Fonte: Adaptado pelos autores de Hooley, Saunders e Piercy (2001) a partir do PEM.

Outro instrumento bem conhecido dos organizadores do PE, o BSC de Kaplan e Norton (2000) utilizado como instrumento de mediação e gestão estratégica do desempenho da prefeitura de Blumenau, foi acionado para acompanhar e avaliar a execução do PEM. Sua utilização permitiu o equilíbrio entre objetivos de curto e longo prazo, como também entre as medidas financeiras e não financeiras, indicadores de tendências e ocorrências e ainda entre as perspectivas interna e externa 
de desempenho. Esse conjunto abrangente de medidas serviu de base para o sistema de medição e gestão estratégica por meio do qual o desempenho organizacional foi mensurado de maneira equilibrada sob as quatro perspectivas propostas na Figura 1, anteriormente: financeira, clientes (os cidadãos), processos internos, aprendizado e crescimento - que refletem a visão e a estratégia do PEM, todos interligados e formando uma relação de causa e efeito.

Inspirados e estimulados pelo PEM a desenvolver o turismo de lazer e eventos, aproveitando as características naturais, a imagem de organização e a tradição alemã da cidade, a Secretaria de Turismo e o Parque Vila Germânica se uniram a vários setores da iniciativa privada para criar e promover a Sommerfest - Festa de Verão. O intuito foi o de solucionar a questão da sazonalidade e atrair o grande volume de turistas que visita o litoral catarinense entre janeiro e fevereiro, também oferecendo opção de lazer aos blumenauenses nesse período do ano. Os organizadores executaram plano de divulgação focado na comunidade local e nas cidades litorâneas.

A Sommerfest está consolidada no calendário de festas de Santa Catarina nos meses de janeiro e fevereiro. Ela é um composto de diversão, folclore, hospitalidade e riqueza cultural que se revela na paixão pela música, pelas danças folclóricas e pela gastronomia típica alemã, elementos marcantes das tradições germânicas trazidas pelos colonizadores há mais de 150 anos.

Divulgada com o slogan "O verão com sotaque alemão", a primeira edição foi realizada com atividades diárias entre 31 de dezembro de 2006 a 20 de fevereiro de 2007, recebendo 30 mil visitantes nas Noites do Sommerfest, público que cresceu para 42.315 pessoas em 2008, conforme dados da Secretaria de Turismo. Se a Oktoberfest nasceu na primavera para superar as enchentes de 1983 e 1984, a Sommerfest brinda o verão e em 2009, dois meses depois de outra enchente, também fortaleceu a imagem de Blumenau como cidade que supera crises com muito trabalho, associado a uma contagiante alegria.

A programação 2008/2009 começou na noite de 31 de dezembro de 2008 com a Neues Jahrfest (Festa de Ano-Novo), organizada com intuito de levantar a autoestima da população, atingida em novembro pela enchente, a festa reuniu mais de 20 mil pessoas. Foi "a nossa festa da virada, pois viramos a página das dificuldades e começamos a escrever um novo capítulo: da superação e recuperação dos ânimos”, salienta Norberto Mette, secretário de turismo da cidade e, também ex-presidente do Parque Vila Germânica.

Integraram a Sommerfest, até 19 de fevereiro, apresentações culturais de bandas típicas, grupos folclóricos e, festival gastronômico em vários restaurantes da cidade. Mas o grande sucesso do evento é atribuído às Noites de Oktoberfest, sempre às quintas-feiras, no Pavilhão 3 da Vila Germânica, que em 2009 reuniu 46.442 pessoas. Nesse período, moradores e turistas aproveitaram a

Revista Ibero-Americana de Estratégia - RIAE, São Paulo, v. 9, n. 2, p. 168-190, mai./ago. 2010. 
"Liquida Blumenau” (liquidação anual de verão no comércio local) e promoção nas tarifas dos hotéis da cidade.

Para conhecer o perfil dos participantes da Sommerfest, a Secretaria Municipal de Comunicação desenvolveu pesquisa em seis diferentes datas de 2009, coincidentes com as Noites de Oktoberfest em janeiro e fevereiro de 2009. Foram entrevistadas 447 pessoas, sendo 208 homens e 239 mulheres que visitaram o Parque Vila Germânica. A maior parcela $(50,11 \%)$ era composta por visitantes com idades entre 19 e 35 anos; 37,14\% de turistas tinham entre 36 e 60 anos. Com relação à situação econômica, a pesquisa revelou que $34,46 \%$ possuía renda individual de $\mathrm{R} \$$ $1.501,00$ a $\mathrm{R} \$ 4.000,00$ e $29,98 \%$ de $\mathrm{R} \$ 501,00$ a $\mathrm{R} \$ 1.500,00$.

Um total de 320 pessoas $(71,59 \%)$ residia em Blumenau e 127 (28,41\%) em outras cidades, das quais 244 (54,59\%) visitavam a Sommerfest - Noite de Oktoberfest - pela primeira vez e 192 (42,95\%) já haviam participado de outras edições. Das 127 pessoas não residentes em Blumenau, 25,20\% afirmaram ser de São Paulo e 24,41\% declararam morar em outras cidades de Santa Catarina. Vários outros estados brasileiros estavam representados, sendo dos cariocas o maior número $(13,39 \%)$ das indicações nesse aspecto. A Sommerfest também recebeu turistas estrangeiros, em pequeno número, vindos da Alemanha, da Argentina e do Chile.

Quando perguntados como tomaram conhecimento da festa (questão de múltipla escolha), 168 responderam ter sido por meio de informações divulgadas por rádio. A indicação de amigos ficou em segundo lugar, com 146 respostas, seguida de jornal (36), outdoor (24), folder e folhetos (22). Agência de turismo e TV empataram com 20 indicações.

Dos entrevistados, $196(43,85 \%)$ eram solteiros e $178(39,82 \%)$ se declararam casados oficialmente ou em união livre. Do total de respondentes, 40,72\% disseram que estavam com um pequeno grupo de amigos, 25,28\% com a família, 14,32\% com o(a) companheiro(a), 10,96\% com um grande grupo de pessoas e apenas 7,38\% sozinhos.

Dentre as ferramentas de comunicação integrada de marketing foram utilizadas: assessoria de imprensa, propaganda, relações-públicas e comunicação interativa. Considerando-se o número de pessoas que frequentam o litoral, público potencial da Sommerfest, o quadro sugere a necessidade de intensificar a divulgação da festa e fortalecer as ações de comunicação de marketing, integrandoas aos objetivos estratégicos do PEM para o turismo. Entre elas as que incluem elaboração de uma rede de informações e de um plano de divulgação da cidade, realização de pesquisas sobre a demanda turística e criação de um calendário anual de eventos. Dessa forma pode-se conseguir uma distribuição mais equitativa de nativos e turistas na composição do público.

Revista Ibero-Americana de Estratégia - RIAE, São Paulo, v. 9, n. 2, p. 168-190, mai./ago. 2010. 
Deve-se considerar que o evento, como produto turístico com grande potencial de atração, foi capaz de otimizar o uso das estruturas turísticas e dinamizar economicamente a cidade e a região onde se realiza, a partir de ações interligadas à economia de sua sede, já que aciona toda a cadeia de atividades relacionadas ao turismo. $\mathrm{O}$ setor de eventos posiciona as cidades promotoras no mercado, criando uma identidade turística e gerando empregos e divisas. Esses lugares se tornam catalisadores dos fluxos turísticos de diversas destinações e é exatamente isso que Blumenau deseja com a Sommerfest, declara Norberto Mette.

\section{CONSIDERAÇÕES FINAIS}

Este artigo teve como objetivo analisar o processo de construção e implantação do Planejamento Estratégico Municipal (PEM) da cidade de Blumenau, em Santa Catarina, com ênfase no turismo. Os resultados revelaram que a administração pública de Blumenau buscou alinhar os seus diferentes planos e planejamentos na perspectiva do desenvolvimento local sustentável e integrado ao contexto socioeconômico regional e nacional. Nesse sentido, articulou a construção de um projeto coletivo que garante a participação de diferentes atores individuais e coletivos nas decisões, enfatizando assim o interesse de agir em bases plurais.

Pode-se verificar que, da articulação entre poder público, iniciativa privada e sociedade civil nasceu o Projeto Blumenau 2020, representado pelo Planejamento Estratégico Municipal (PEM) para o período de 2005 a 2020. Articulado a ele está o projeto estruturador para desenvolver o turismo de lazer e eventos, aproveitando as características naturais, a imagem de organização e a tradição alemã da cidade, tendo como grande desafio solucionar o problema da sazonalidade turística.

Os resultados mostraram um alinhamento com a literatura estudada, principalmente no que concerne ao modelo proposto por Brandenburger e Nalebuff (1995) e apresentado na Figura 1, anteriormente. Por ele pode-se identificar que haveria necessidade de usar todos os recursos disponíveis, por meio da articulação do governo municipal - o que também se verificou estar de acordo com Besanko, Dranove e Shanley (2000) - em prol da manutenção de Blumenau como um dos principais destinos turísticos do Brasil. A organização típica da cultura germânica possibilitou o alto nível de atividade dos complementadores ao garantir o bom atendimento em hotéis, restaurantes, transportes, centros de informação para o turista e limpeza da cidade. A estratégia vai ao encontro também da proposta da Visão Baseada em Recursos (Amit e Schoemaker, 1993; Rumelt, Schendel, Teece, 1994). 
As estratégia genérica de diferenciação (Porter, 1986) se mostrou presente na decisão dos articuladores da estratégia de explorar a alta qualidade de vida e educação do blumenauense em prol da imagem da cidade na prestação de serviços. A solução da Sommerfest se mostrou também coerente com a proposta de estratégia emergente de Mintzberg, Ahlstrand, Lampel (2000), após os indícios revelarem que havia espaço e oportunidade para mais esse evento, apesar da combinação de verão com germanidade. A flexibilidade do PEM se mostrou efetiva, após a tragédia de 2008, com a alocação de verbas para cuidar do ativo natural e humano da cidade.

A utilização do roteiro de análise proposto por Hooley, Saunders e Piercy (2001) e transformado na Matriz do Posicionamento Estratégico que orientou e organizou o PEM foi outra feliz descoberta de aderência da prática à teoria, assim como o uso do BSC como forma de auxílio à definição da estratégia e monitoramento das ações desencadeadas para dar forma ao PEM.

Constatou-se na pesquisa um movimento sinérgico de forças em torno do turismo como negócio que requer investimento, especialização e estratégias adequadas de promoção e divulgação.

A "Alemanha tropical” quer ser vista além da vitrine da Oktoberfest e mostrar seu potencial turístico o ano inteiro. A criação da Sommerfest foi uma continuação coerente com a estratégia original e os recursos da cidade, conseguindo atrair os turistas que visitam o litoral catarinense na alta temporada, entre dezembro e março.

Para isso, aproveitou estruturas já existentes e se ancorou em seu principal produto turístico para realizar uma festa de verão com sotaque alemão, pautada nas Noites de Oktoberfest. Mas há muito ainda por fazer nessa direção. Com três edições já realizadas, a Sommerfest se constitui mais em um encontro festivo entre blumenauenses que um evento de atratividade de público externo. Por isso a necessidade, admitida pelos gestores públicos, de estrategicamente ampliar a visibilidade desse evento e desenvolver outros, capazes de contribuir para o fortalecimento do setor, vislumbrando "tornar Blumenau a melhor cidade do país para viver".

A principal contribuição da pesquisa para o campo acadêmico foi mostrar a ligação da estratégia, no caso Blumenau e sua opção pelo turismo como fator de desenvolvimento local, com as teorias e ferramentas de planejamento estratégico aplicadas em uma gestão municipal. Acreditase que para o campo de estudos sobre o turismo os resultados apresentados podem servir de inspiração para novos estudos, talvez de casos múltiplos, o que superaria as limitações do presente caso limitado a um só município.

Para o campo gerencial, pode-se esperar que o exemplo sirva para mostrar a aproximação entre a teoria e a prática da gestão pública, assim como, ajudar a reflexão sobre os novos tempos do turismo de eventos, agora pautado por maior precisão e profissionalismo.

Revista Ibero-Americana de Estratégia - RIAE, São Paulo, v. 9, n. 2, p. 168-190, mai./ago. 2010. 
Estratégia Municipal para o Desenvolvimento Local: O Caso do Planejamento Estratégico de Blumenau-SC

\section{REFERÊNCIAS}

Acselrad, H. Território e poder: a política das escalas. In: FISCHER, T. Gestão do desenvolvimento e poderes locais: marcos teóricos e avaliação. Salvador: Casa da Qualidade, 2002, p. 33-44.

Amit, R.; Schoemaker, P. J. Strategic assets and organisational rent. Strategic Management Journal, v. 14, p. 33-46, Jan. 1993.

Barney, J. Firm resources and sustained competitive advantage. Journal of Management, v. 17, n. 1, p. 99-120, March 1991.

Besanko, D.; Dranove, D.; Shanley, M. Economics of Strategy. New York: John Wiley, 2000.

Brasil. Constituição da República Federativa do Brasil, promulgada em 5 de outubro de 1988. 38. ed. São Paulo: Saraiva, 2006.

Brasil. Estatuto da Cidade: guia para implementação pelos municípios e cidades. 2. ed. Brasília: Câmara dos Deputados, coordenação de publicações, 2002.

Brandenburger, A. M.; Nalebuff, B.J. The right game: use game theory to shape strategy, Harvard Business Review, july-august, 1995, pp. 57-72.

Buarque, S. C. Construindo o desenvolvimento local sustentável: metodologia e planejamento. 2. ed. Rio de Janeiro: Garamond, 2002.

Buarque, S. C.; Bezerra, L. Projeto de desenvolvimento municipal sustentável: bases referenciais. Projeto Áridas (mimeo.), dezembro de 1994.

Carvalho, J. L. F.; Vergara, S. C. A fenomenologia e a pesquisa dos espaços de serviços. Revista de Administração de Empresas - RAE, v. 42, n. 3, p. 78-91, jul./set. 2002.

Costa, B.K.; Fishmann, A.; Silva, L.M.T. Escolas de Formulação de Estratégias: Um Estudo em Localidades Receptivas de Turismo no Estado de São Paulo. Anais do XXXII Encontro da AnPAD, Rio de Janeiro, 2008

Day, G. S. The capabilities of market-driven organizations. Journal of Marketing, v. 58, n. 3, p. 37-52, 1994.

Eisenhardt, K.M. Building theory from case study research. Academy of Management Review, 14(4), 1989, (532-550).

http://dx.doi.org/10.2307/258557

http://dx.doi.org/10.5465/AMR.1989.4308385

Revista Ibero-Americana de Estratégia - RIAE, São Paulo, v. 9, n. 2, p. 168-190, mai./ago. 2010. 
Fazzini, C.; Palladino, R. Turismo de eventos. Revista Turismo em Números. São Paulo, n.15, p. 816, out. 2003.

Ferreira, M. R.. Planejamento regional do turismo. Estudos Turísticos. Lisboa, n. 0, p 41-48, $1^{\circ}$ semestre 1995.

Fischer, T. Gestão do desenvolvimento e poderes locais: marcos teóricos e avaliação. Salvador: Casa da Qualidade, 2002.

Furtado, J. R. C. Elementos de direito financeiro: sistema orçamentário (PPA, LDO e LOA) despesa pública, receita pública, responsabilidade fiscal, controle da execução orçamentária. Belo Horizonte: Fórum, 2009.

Goeldner, C. R.; Ritchie, J. R. B.; Mcintosh, R. W. Turismo: princípios, práticas e filosofias. 8 ed. Porto Alegre: Bookman, 2002.

Hooley, G., Sauders, J.A., Piercy, N.F. Estratégia de Marketing e Posicionamento Competitivo, $2^{\mathrm{a}}$ edição -São Paulo: Prentice Hall, 2001

Ingelstam, L. La planificación del desarrollo a largo prazo: notas sobre su esencia y metodología. Revista de la CEPAL, n. 31, Santiago, 1987.

Irving, M. A. Turismo: o desafio da sustentabilidade. São Paulo: Futura, 2002.

Kaplan, R. S.; Norton, D. P. O organização voltada para a estratégia: como as empresas que adotam Balanced Scorecard prosperam nonovo ambiente de negócios. Rio de Janeiro: Campus, 2000.

Licklorish, L. J.; Jenkins, C.L. Introdução ao Turismo. Rio de Janeiro: Campus, 2000.

Mathews, J. A. A resource-based view of Schumpeterian economic dynamics. Journal of Evolutionary Economics, v. 12, n. 1, p. 29-54, 2002.

Mathieson, A.; Wall, G. Tourism: economic, physical and social impacts. Essex, UK: Longman, 1996 (Special Bulletin)

Miles, M. B.; Huberman, A. M. Qualitative data analysis. Thousand Oaks: Sage Publications, 1994.

Mintzberg, H.; Ahlstrand, B.; Lampel, J. Safári de estratégia. Porto Alegre: Bookman, 2000. The rise and fall of strategic planning. New York: Prentice Hall, 1994.

Moesch, M. A produção do saber turístico. São Paulo: Contexto, 2000.

Revista Ibero-Americana de Estratégia - RIAE, São Paulo, v. 9, n. 2, p. 168-190, mai./ago. 2010. 
Neves, J. L. Pesquisa qualitativa: características, usos e possibilidades. Caderno de Pesquisa em Administração, v.1, n.3, p. 1-5, 1996.

Pereira, B. M. Carnaval e turismo: pós-modernidade na avenida. In: GASTAL, S.; Castrogiovanni, A. C. (Orgs.). Turismo na pós-modernidade: (des)inquietações. Porto Alegre: Edipucrs, 2003, p. 97-110.

Porter, M. Estratégia competitiva: técnicas para análise da indústria e da concorrência. Rio de Janeiro: Campus, 1986.

Pfeiffer, P. Planejamento estratégico municipal no Brasil: uma nova abordagem [Textos para discussão n. 37]. Brasília: Escola Nacional de Administração Pública, 2000.

Pizam, A. Tourism's impacts: the social costs to the destination as perceived by its residents. Journal of Travel Research, Thousand Oaks, v.16, n.4, p. 8-12, dec.,1978 http://dx.doi.org/10.1177/004728757801600402

Prefeitura de Blumenau. Planejamento Estratégico 2005-2020.

Rezende, D. A.; Castor, B. V. J. Planejamento estratégico municipal: empreendedorismo participativo nas cidades, prefeituras e organizações públicas. Rio de Janeiro: Brasport, 2006.

Rumelt, R. P.; Schendel, D.; Teece, D. J. Fundamental issues in strategy: a research agenda. Boston: Harvard Business School Press, 1994.

Salem, G., Jones, E., Morgan, N. An overview of events management, in Festival and events management: an international arts and culture perspective, Yeoman, I., Robertson, M. AliKnight, J. (org). Butterworth-Heinemann, 2004 - 418 páginas

Santur - Santa Catarina Turismo. Disponível em: <www.santur.gov.br〉. Acesso em:12 out. 2009.

Seddigli, H.R.; Theocharous, A.C. A model of tourism destination choice: a theoretical and empirical analysis. Tourism Management, Oxford, v. 23, n.4, p. 448-75, 2002

Silva, J.M.; Costenaro, A. Planejamento Estratégico: um recurso para o desenvolvimento do turismo municipal. Anais do XXVIII Encontro da AnPAD, Curitiba, 2004

Swarbrooke, J. Turismo sustentável: conceitos e impacto ambiental. São Paulo: Aleph, 2000.

Teixeira, R. F.; Pacheco, M. E. C. Pesquisa social e a valorização da abordagem qualitativa no curso de administração: a quebra dos paradigmas científicos. Caderno de Pesquisa em Administração. São Paulo, v. 12, n. 1, p. 55-68, jan./mar. 2005.

Revista Ibero-Americana de Estratégia - RIAE, São Paulo, v. 9, n. 2, p. 168-190, mai./ago. 2010. 
Tomio, D. Estrutura do planejamento estratégico do turismo. Revista de Negócios. Blumenau, v. 5, n. 3, p. 39-52, jul./set. 2000 .

Triviños, A. N. S. Introdução à pesquisa em Ciências Sociais: a pesquisa qualitativa em educação. São Paulo: Atlas, 1992.

Ultramari, C.; Rezende, D. A. Planejamento estratégico e Planos Diretores Municipais: referenciais e bases de aplicação. Rev. Adm. Contemporânea, v.l. 12, n. 3, p. 717-739, 2008.

Weber, W. Estratégias Genéricas de Competição: sua Evolução, Importância e a Influência de Michael Porter. Anais do IX SEMEAD, 2006

Vieira, M. M. F.; Zouan, D. M. (Orgs.). Pesquisa qualitativa em Administração. Rio de Janeiro: Fundação Getúlio Vargas, 2004.

Yin, Robert K. Estudo de caso: planejamento e métodos. 2. ed. Porto Alegre: Bookman. 2001.

Recebido: 05/05/2010

Aprovado: 08/09/2010

Revista Ibero-Americana de Estratégia - RIAE, São Paulo, v. 9, n. 2, p. 168-190, mai./ago. 2010. 